\title{
Moving Towards a Reliability-Oriented Design Approach of Low-Voltage Electrical Machines by Including Insulation Thermal Aging Considerations
}

\author{
Paolo Giangrande, Senior Member, IEEE, Vincenzo Madonna, Student Member, IEEE, Stefano Nuzzo, Member, \\ IEEE and Michael Galea, Senior Member, IEEE
}

\begin{abstract}
Electrical machines are required to consistently perform their intended mission over a specified timeframe. The move towards transportation electrification made the electrical machines' reliability an even stringent and predominant requirement, since a failure might cause severe economic losses, as well as, endanger human lives. Traditionally, the design procedure of motors conceived for safety-critical applications mainly relies on over-engineering approaches. However, a paradigm shift is recently taking place and physics of failure approaches / methodologies are employed to meet the reliability figures, while delivering an optimal design. The present work proposes and outlines a reliability-oriented design for low-voltage electrical machines. Thermal accelerated aging tests are preliminarily carried out on custom-built specimens. Once the aging trend of the turn-to-turn insulation system is assessed, the thermal endurance graph at several percentile values is determined and lifetime models are developed, for both constant and variable temperature operations. Finally, these models are used to predict the turn-to-turn insulation lifetime of motors meant for aerospace and automotive applications.
\end{abstract}

Index Terms - Design of Experiments, Accelerated Thermal Aging Tests, Dielectric Breakdown, Electrical Machines Insulation, Physics of Failure.

\section{INTRODUCTION}

$\mathrm{E}$ LECTRICAL machines (EMs) are found in several fields

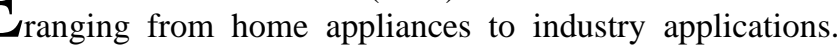
Their inherent multi-domain nature involves electromagnetic, thermal and mechanical aspects, therefore a multi-disciplinary design approach is commonly required for complying with the available specifications [1]. The EM design process has been progressively refined over time, and nowadays, EM designers can rely on various engineering tools, which enable accurate and optimal designs. In fact, performance-oriented EM design already allows to develop EMs that can achieve excellent performance in terms of

This work was partially funded from the Clean Sky 2 Joint Undertaking under the European Union's Horizon 2020 research and innovation programme under grant agreements no. 807081 and 821023 . This work was also supported by the University of Nottingham Propulsion Futures Beacon through the projects PF042 and PF054a.

Paolo Giangrande, Vincenzo Madonna, Stefano Nuzzo and Michael Galea are with the Power Electronics, Machines and Control (PEMC) group within the University of Nottingham, United Kingdom (emails: efficiency and power density [2-4].

In the last decade, EMs also gained relevant access to the automotive and aerospace sectors due to the transportation electrification, which represents a great opportunity for lowering greenhouse gases emissions and partially address the climate change challenge [5-7]. For mobile applications, EMs are demanded to simultaneously feature high performance and appropriate reliability levels. Accordingly, a compact and light EM design is desirable because of the limited space and vehicle weight restrictions. Considerable power ratings are frequently preferable to avoid the adoption of mechanical devices, such as gearbox or harmonic drives, which add weight to the system and reduce its overall reliability (i.e. higher component count) $[8,9]$. The increase in the power density is generally obtained by enhancing the thermal load, although the thermal limit (i.e. insulation thermal class) is one of the main constraining factors $[10,11]$. Indeed, prolonged exposures to uncontrolled over-temperatures might trigger a significant aging and degradation of the insulation, compromising its dielectric properties $[12,13]$. It is worth noting that among the different causes of failures affecting EMs, studies revealed that approximately $30 \%$ of the failures are associated to winding faults $[14,15]$.

Considering the EM lifetime, the insulation system often represents the bottleneck and the reliability requirement is usually met through its over-engineering by using safety factors based on experience and rules of thumb, as shown in Fig. 1, where the flowchart of a typical performance-oriented EM design is reported. Nevertheless, such an approach can lead to a lower slot fill factor that negatively impacts the EM weight and cost, along with the dissipation of the heat produced within the slot [16]. Additionally, the capability of the insulation material is not properly exploited because of its over-specification, resulting in an insulation system that greatly outperforms the specified EM life. It is therefore clear that a design contrast between operational performance and reliability exists and it can ensue in conflicting design choices. To overcome this challenge and to pursue a convenient balance between performance and reliability, a paradigm shift from

p.giangrande@nottingham.ac.uk,

ezzvm2@exmail.nottingham.ac.uk, ezzsn@exmail.nottingham.ac.uk, michael.galea@nottingham.ac.uk).

Stefano Nuzzo is also with Department of Engineering Enzo Ferrari, within Università degli Studi di Modena e Reggio Emilia, Italy (email: Stefano.Nuzzo@unimore.it).

Michael Galea is also with the and Key Laboratory of More Electric Aircraft Technology of Zhejiang Province, University of Nottingham Ningbo China (email: Michael.Galea@nottingham.edu.cn). 
performance- to reliability-oriented designs is needed [17]. Physics of failure (PoF) methodologies enable the precise knowledge, understanding and mapping of the insulation degradation, which allow for a better exploitation of the insulating materials, securing a satisfactory reliability level without undermining the EM's weight, volume or cost [18-19].

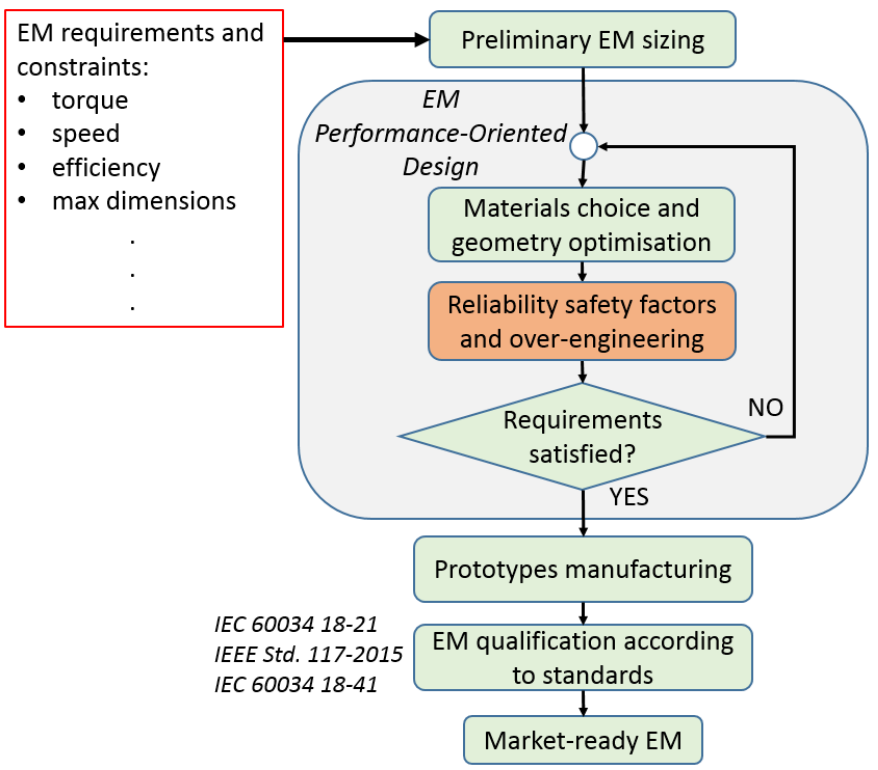

Fig. 1. Flowchart of the performance-oriented EM design.

This paper presents a modern approach for the design of EMs, where reliability becomes an objective from the very start of the design process (i.e. reliability-oriented design), while still achieving the performance requirements demanded nowadays. Hence, the current work aims at outlining the procedure and the primary steps for implementing a possible reliability-oriented EM design strategy, where PoF methodologies are applied to the EM windings. Based on the concept of 'design of experiments' [20], the turn-to-turn insulation sub-system (i.e. the weakest one from a failure prospective) of low-voltage random-wound EMs is investigated. Accelerated thermal aging tests are performed on custom-designed specimens mirroring the basic structure of an EM's stator core and a multi-percentile thermal endurance plot (i.e. Arrhenius graph) is determined. The latter represents the starting point for developing lifetime models applicable to EMs equipped with the assessed insulation system (i.e. enamelled wire), although the proposed methodology can be extended to insulation materials featuring a different chemical composition. Lifetime degradation models suitable for both continuous and variable services, built respectively on the Arrhenius and the Arrhenius-Miner laws, are presented and then used at the design stage of low-voltage random-wound EMs, according to the reliability level established by the application under study. Finally, the applicability of the implemented models is proven by evaluating the predicted lifetime of two study-cases, namely one driving an aerospace electromechanical actuator (EMA) and the other for a fully-electric vehicle.

The new design philosophy being introduced here combines the benefits and strengths of PoF methodologies, statistical analysis and thermal lifetime modelling. Thus, this paper is enhancing the knowledge regarding 1) how the findings of accelerated thermal aging tests can be integrated in the EM design process through appropriate lifetime models and 2) how lifetime models featuring different levels of reliability (i.e. percentiles of time-to-failure) can be employed at the EM design stage. Such knowledge will empower the much-need move towards more reliability-oriented EM designs.

\section{STUdy ASSESSMENT AND CONSIDERATIONS}

PoF methodologies permit the implementation of reliabilityoriented EM design through the adoption of lifetime models that predict the insulation system life [21]. A graphic representation of the reliability-oriented EM design approach is given in Fig. 2, where its flowchart is illustrated. Compared to the performance-oriented EM design of Fig. 1, where the reliability figures are achieved via safety factors, in a reliability-oriented strategy, the reliability is considered from the early design stage (i.e. reliability as design objective) and it is evaluated using PoF methodologies (i.e. accelerated aging tests whose results allow to develop lifetime models).

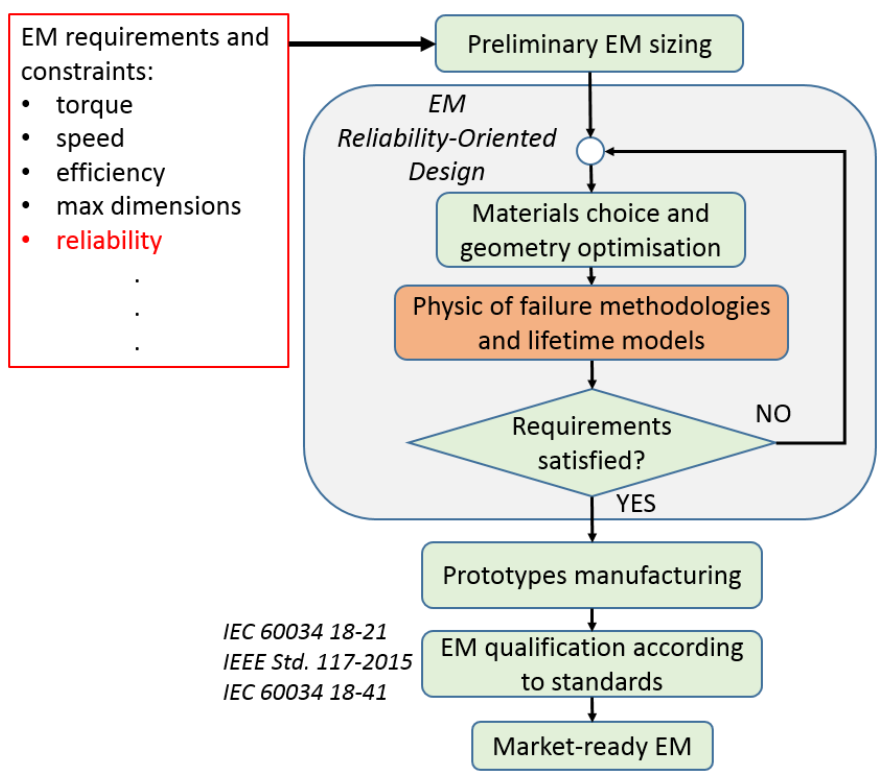

Fig. 2. Flowchart of the reliability-oriented EM design.

Insulation system lifetime analysis is carried out through accelerated aging tests, where degrading stresses, such as thermal, electrical, mechanical and environmental (e.g. moisture), are applied at higher intensity levels than those usually experienced in ordinary service conditions by the insulation system [22]. The data sets collected during these 'forced' abnormal circumstances are then utilized to statistically extrapolate the insulation system lifetime under normal operating conditions relying on a lifetime probability distribution. In reality, the aging factors (or stresses) act concurrently on the insulation system and thus, a truly representative lifetime prediction can only be reached by implementing multi-stress lifetime models [23-26]. Although accurate, multi-stress models are complex and exceedingly time consuming to build [20]. Indeed, their complexity is primarily due to the challenge of distinguishing and quantifying the aging contribution caused by the simultaneous action of two or more aging factors (i.e. coupled or combined aging effect), since the 
superimposition principle cannot be applied [27]. Consequently, the combined aging effect are empirically appraised.

To overcome the challenges of multi-stress models, an alternative approach consists in identifying the prevailing aging mechanism and developing a single-stress model, which could then be extended / integrated into a comprehensive model (i.e. multi-stress model) later on. The assumption of prevailing aging factor is very common in literature [27, 28] and standards [29]. It is based on the consideration that during their typical operational cycles, most insulation systems experience a single dominant stress, which predominantly influences their lifetime, while other stresses (i.e. secondary aging factors) have a negligible effect [27-29]. This enables and supports the use of single-stress lifetime models for predicting the insulation lifetime.

\section{A. Aging stress and prevailing aging factor}

In this study, the hypothesis of thermal stress (i.e. temperature) as prevailing aging factor is made. Therefore, the discussed lifetime evaluation relies on single-stress lifetime models (i.e. Arrhenius and Arrhenius-Miner models), which are applicable and valid only in case of low-voltage EMs, where the insulation aging is principally caused by temperature. However, EMs' insulation systems are exposed to other stresses throughout their service life. Thus, considerations on partial discharges (PD), vibrations and moisture are necessary to better frame the application field of this work.

The hygroscopic nature of many insulating materials results in moisture (i.e. humidity) being drawn into the body of the insulation either from the atmospheric air (e.g. air cooled EMs) or from leakage of water (e.g. water cooled EMs) [30]. Despite such inherent property of the insulation system, the moisture can be assumed as secondary aging factor, when conventional EM applications are analysed (e.g. no-water submerged EMs). In this case, moisture does not provide a significant aging contribution on its own, but it features the propensity of intensifying the occurrence of other stresses, e.g. PD activity $[17,31]$.

In many applications, mechanical stresses (i.e. vibrations) are frequent and their lifetime impact is more severe on aged insulation systems, since the enamel layer tends to become brittle and vibrations might lead to its detachment [13]. To prevent the enamel detachment, precautions should be taken at the EM design and manufacturing stages, e.g. using silicone-based varnishes.

The risk of PD inception depends on the variable speed drive (VSD) properties and it is closely related to the rise time of the waveform feeding the EM (i.e. $d V / d t$ ). In fact, the combination among power converter, connecting cable and EM will raise the probability of electrical stress, due to the enhancement of the voltage at the EM terminals [32,33]. This is a sensitive topic and calls for a detailed examination, which is addressed in the next sub-section.

\section{B. Partial discharge risk assessment}

Low-voltage EMs (i.e. with rated voltage lower than $700 \mathrm{Vrms}$ ) are normally equipped with random-wound windings and their overall insulation system is composed by several sub-systems, such as turn-to-turn, phase-to-phase and phase-to-ground ones. In general, the turn-to-turn insulation sub-system is recognized as the weakest point in terms of expected failure, since it comprises only a thin layer of enamel featuring organic chemical composition (e.g. polyamide, polyimide, polyester-imide etc.) [12]. For this reason, the presented investigation deals on the inter-turn insulation only.

In VSDs, the EM's insulation system is susceptible to 'heavy' electrical stresses. Indeed, the voltage at the EM's terminals might reveal an amplitude greater than that at the output of the converter feeding it, due to the impedance mismatch between motor and connecting cable [32]. Hence, low-voltage random-wound EMs are likely to suffer from PD activity, which in case of organic insulation (i.e. Type I insulation) leads to the insulation breakdown in a very short time period [34]. Focusing only on the turn-to-turn insulation, a PD-free design is ensured when the minimum PD inception voltage (PDIV), expressed by (1), is higher than the peak voltage occurring across two adjacent turns [35].

$$
P D I V_{\min t-t}=0.7 \cdot K\left(t_{r}\right) \cdot V_{D C} \cdot O F \cdot E F
$$

In (1), PDIV $V_{\text {mint }-t}$ is the minimum turn-to-turn PDIV, $K\left(t_{r}\right)$ is a coefficient closely related to the applied waveform rise time $t_{r}, V_{D C}$ is the DC-link voltage, $O F$ is the overshooting factor and $E F$ is the enhancement factor depending on the thermal class, grounding and aging. According to the VSD and magnet wire specifications, the appropriate values of $K\left(t_{r}\right), O F$ and $E F$ can be found in [36]. In particular, the $O F$ ranges from 1.1 to 2 , the $E F$ varies between 1.25 and 1.65 , while $K\left(t_{r}\right)=1$ in the worst-case scenario (i.e. first turn close to the last one and very short rise time). Assuming a two-level converter with $270 \mathrm{~V}$ on the DC-link and unipolar waveform, the $P D I V_{\min t-t}$ obtained through (1) corresponds to $330 \mathrm{Vrms}$, when $K\left(t_{r}\right)=1, E F=$ 1.4 and $O F=1.25$ (i.e. connection cable about $10 \mathrm{~m}$ long and $200 \mathrm{~ns}$ rise time) [37]. For the magnet wire under examination, whose characteristics are discussed in the next sub-section, the turn-to-turn PDIV has been measured using a Techimp PD-Base $\AA$ together with a transverse electromagnetic (TEM) antenna as PD detector, and values between $480 \mathrm{Vrms}$ and $500 \mathrm{Vrms}$ have been recorded. Thus, it is possible to safely state that the PD risk is reasonably confined, if the above VSD properties are fulfilled (i.e. $270 \mathrm{~V}$ on the DC-link, two-level power converter based on conventional silicon IGBT and short connection cable between EM and power converter).

\section{Specimens and magnet wire}

Considering that the insulation is free from PD (i.e. PD-free EM design), it is plausible to suppose the thermal aging as the main insulation stress factor (i.e. prevailing aging mechanism) [27-29]. Hence, the influence of the thermal stress is evaluated via accelerated thermal aging tests at constant temperature, which are performed on purposely-built motorettes [38, 39], such as those shown in Fig. 3. The motorette's core is made of non-laminated aluminium, due to the need of minimising both manufacturing costs and times. In fact, the latter would have been higher for laminated motorettes in silicon steel or cobalt-iron alloys. It is noteworthy to mention that the choice of the motorette's core material does not affect the thermal aging of the turn-to-turn insulation (i.e. insulation system under analysis). Therefore, any core material could have been utilized for manufacturing the motorettes. 


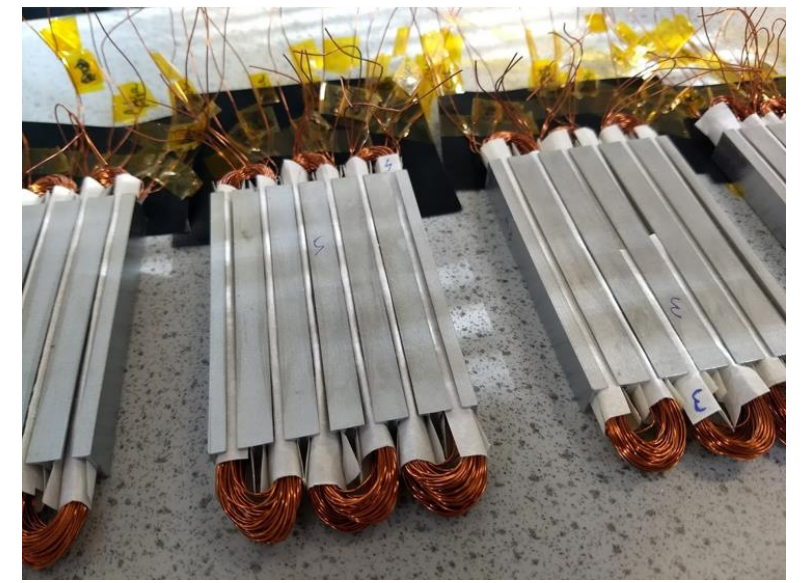

Fig. 3. Motorettes adopted for the accelerated thermal aging tests.

Each motorette features 6 slots and a tooth-wound, double-layer winding with the 2 layers (i.e. 2 active sides of different coils) located radially within the slot, thus resulting in a total of 6 coils per motorette. This concept is illustrated in Fig. 4, where the motorette winding arrangement is highlighted. In terms of slot fill factor (i.e. the ratio between copper and slot areas), a value of $\approx 0.5$ is achieved, while the coils are not impregnated. To assess the turn-to-turn dielectric properties during the diagnostic session, every coil is characterized by 2 parallel strands, across which the testing excitation voltage is applied. Taking as example the coil indicated as "\#1A1" in Fig. 4, the 2 parallel strands are marked with "\#1A1_a" and "\#1A1_b" and the same logic is extended to all of the 6 coils.

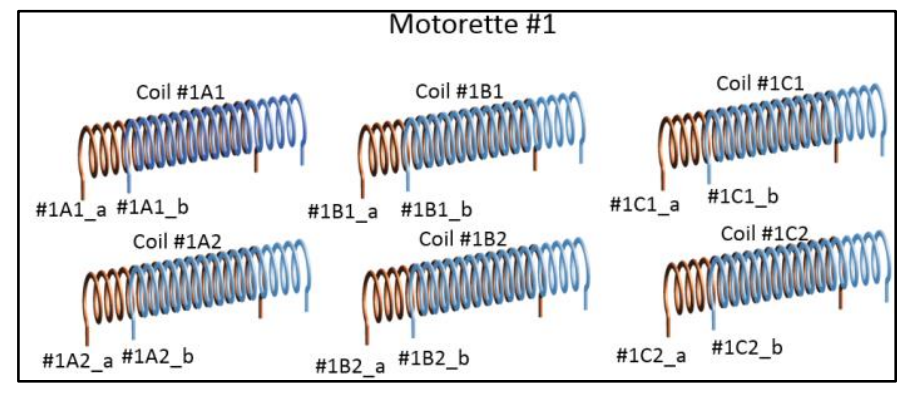

Fig. 4. Overview of the motorette winding layout.

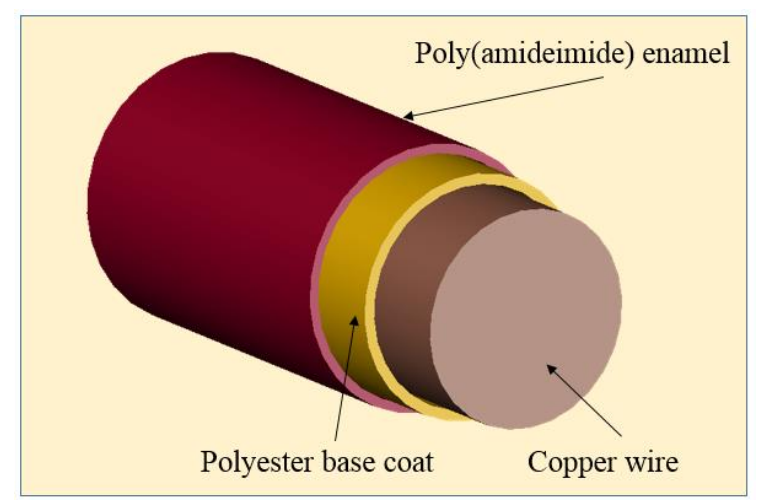

Fig. 5. Illustration of the dual-coat magnet wire.

A final consideration is related to the enamelled magnet wire adopted for the accelerated aging tests campaign. The winding is made of a Class 200, Grade 2, $0.4 \mathrm{~mm}$ diameter magnet wire and its insulating enamel layer consists of a modified polyester base-coat reinforced with a polyamide-imide over-coat (i.e. dual-coat magnet wire), as depicted in Fig. 5. Dual-coat magnet wires are commonly employed in high performance EMs, since they possess better heat-shock and abrasion resistance than monolithic coating (i.e. single-coat magnet wire). In fact, the modified polyester base-coat provides a good adhesion to the copper and high flexibility, whereas the polyamide-imide over-coat leads to a high abrasion resistance and high temperature endurance [40]. Therefore, the combination of polyesters with polyamide-imide makes the magnet wire suitable for faster winding and insertion while improving the thermal class at a slightly additional cost [41].

\section{TEST CAMPAIGN DESCRIPTION}

In total, a set of 15 motorettes is manufactured and wound according to the winding layout of Fig. 4 with the magnet wire introduced in the previous section. Following the common practice, a Nomex ${ }^{\circledR}$ type slot-liner has been placed within the slots (thickness $0.13 \mathrm{~mm}$ ) to avoid any direct contact between enamel and motorette core (i.e. strengthening the phase-to-ground insulation) and also to prevent enamel scratching during the coils insertion.

In most industrial products, the thermal class claimed by the magnet wire manufacturers is the outcome of accelerated aging tests, where the thermal stress is applied to sets of twisted pairs [42]. Consequently, the thermal class (i.e. temperature level where the enamel lifetime corresponds to 20,000 hours) resulting from the EM thermal qualification might differ from the one provided on the magnet wire datasheet. Indeed, additional failure modes might be induced when motorettes are considered (as opposed to twisted pairs). On the other hand, the motorettes give a much more realistic representation of the actual wire-laying condition found in an EM, than twisted pairs.

For a specific aging temperature value, the single accelerated thermal test has been performed on a set of 5 motorettes, counting an overall number of 30 coils (i.e. 6 coils per motorette). For the presented study, a relatively high number of samples has been chosen to ensure statistical validity of the collected data and to account for any discrepancies and variations in the physical make-up of the random-wound winding. However, a minimum number of 10 samples might have been also used, as advised by technical standard [38].

At groups of 5, the samples are aged at a different temperature above the magnet wire thermal class (i.e. $200{ }^{\circ} \mathrm{C}$ ), employing a high precision ventilated oven and following the test campaign procedure summarized in the flowchart of Fig. 6 . Three aging temperatures, separated by an interval of $20^{\circ} \mathrm{C}$ [38], are selected and set at 230,250 and $270{ }^{\circ} \mathrm{C}$. The hysteresis band of the oven temperature control has been set at $\pm 1{ }^{\circ} \mathrm{C}$ around the reference temperature. For each aging temperature value, the samples have been exposed to a thermal cycle, whose duration depends on the testing temperature level [38], as detailed in Table I. After every thermal exposure, the motorettes are naturally cooled down to room temperature before running the insulation diagnostic session. The examined magnet wire is expected to feature a maximum turn-to-turn voltage below the minimum PDIV (i.e. $480 \div 500$ Vrms experimentally determined). In other words, it is supposed that no inter-turn PD activity occurs in standard operating conditions. Under this assumption, the dielectric breakdown is selected as end-of-life criterion for assessing the 
dielectric status of the aged specimens. For the sake of completeness, it is important to clarify that the end-of-life criterion should have been the PD inception, in case the PD-free hypothesis was not fulfilled [43]. Nonetheless, the end-of-life criterion's choice does not undermine the validity of the analysis presented hereinafter.

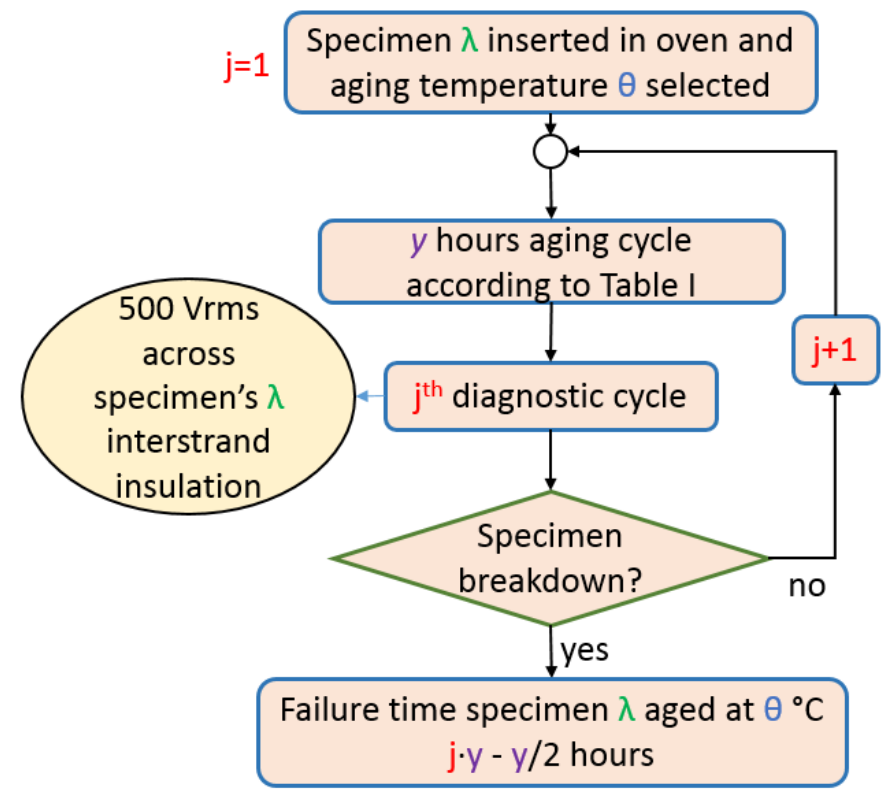

Fig. 6. Flowchart of the accelerated thermal aging tests.

During the diagnostic session, the turn-to-turn dielectric strength has been assessed through the dielectric voltage-withstand test, commonly known as the AC hipot test. This is a pass/fail test consisting in applying a sinusoidal voltage (i.e. diagnostic voltage) [38], with $500 \mathrm{Vrms}$ amplitude and $50 \mathrm{~Hz}$ frequency, across the strands belonging to the same coil, e.g. according to the layout of Fig. 2 the voltage is applied between the terminals marked as "\#1A1_a" and "\#1A1_b", for the coil "\#1A1". The diagnostic voltage, which should not be considered as an electrical stress [38], is held for a time window of one minute $[44,45]$ using the dissipation factor tester (i.e. Megger ${ }^{\circledR}$ Delta 4000). If the sample is not able to withstand the $500 \mathrm{Vrms}$ (i.e. turn-to-turn insulation breakdown), it is then labelled as 'dead' and its time-to-failure is recorded. The latter is calculated as the sum of the total thermal exposure hours minus the duration of half thermal cycle [46]. This means that the end-of-life is estimated at half of the last thermal cycle. Once the diagnostic session is completed (i.e. all the 'alive' coils have been tested), a new thermal exposure cycle is run and the accelerated test (for a defined temperature) ends when all samples fail the diagnostic test.

In the present study, the amplitude of the diagnostic voltage is chosen equal to the magnet wire's PDIV value. Indeed, performing the AC hipot tests at diagnostic voltage amplitudes higher than the wire's PDIV (i.e. $>500 \mathrm{Vrms}$ ) would induce enhanced PD activity within the insulation, which will lead to a premature insulation breakdown; namely, the insulation breakdown would not be ascribed to the thermal aging, but it will be due to the PD activity. On the other hand, diagnostic voltage amplitudes lower than the wire's PDIV (i.e. $<500 \mathrm{Vrms}$ ) would lead to over-conservative single-stress lifetime models, since the turn-to-turn dielectric strength would not be properly assessed.

Table I Duration of the thermal exposure cycles [38]

\begin{tabular}{|c|c|}
\hline Aging temperature [ ${ }^{\circ} \mathbf{C}$ ] & Cycle exposure time [h] \\
\hline 230 & 384 \\
\hline 250 & 96 \\
\hline 270 & 24 \\
\hline
\end{tabular}

\section{Statistical ANALYsis AND Test CAMPAign Results}

The time-to-failures collected over the accelerated thermal aging campaign (i.e. high aging level) are employed to extrapolate the time-to-failure distribution at normal operating conditions (i.e. service aging level) considering different percentiles [42]. This goal is achieved through the development of an appropriate stochastic life model, based either on physical laws or on empirical experience of data fitting, whose parameters are estimated through a probability distribution function [46]. Among the possible probability distribution functions, the Weibull distribution is the prevalent and most popular choice for handling time-to-failures related to the breakdown in solid insulation [22, 43]. Indeed, it can be applied on a limited number of data (e.g. time-to-failures) allowing also their censoring without compromising the outcome accuracy. Besides, the Weibull distribution is characterized by a closed-form solution for the integral of the probability density function, which empowers a simple calculation of the cumulative probability function [22]. The recorded time-to-failures are statistically post-processed using a two-parameter Weibull distribution, whose cumulative distribution function (CDF) $F(t)$ is given by (2) and accounts for the sample population that will experience the insulation breakdown by the time $t$.

$$
F(t)=1-e^{-(t / \alpha)^{\beta}}
$$

In (2), $\alpha$ is known as the scale parameter $(\alpha>0)$ and corresponds to the $63.2 \%$ percentile of the lifetime (i.e. the time needed by the $63.2 \%$ of the samples to reach the end-of-life), while $\beta$ is called shape parameter $(\beta>0)$ and provides an idea regarding the data dispersion (e.g. variance). Besides, the shape parameter is associated to the Weibull distribution slope and it is a dimensionless quantity. These parameters (i.e. $\alpha$ and $\beta$ ) are determined via a graphical method based on the linear regression approach. For each performed accelerated thermal aging test (i.e. 230, 250 and $270{ }^{\circ} \mathrm{C}$ ), the time-to-failures $t_{i}$ are sorted in ascending order and they represent the abscissa values of the Weibull probability plot. As discussed in [22], the Weibull CDF in (2) is linearized by taking twice the natural logarithm, as detailed in (3).

$$
\ln \left[\ln \left(\frac{1}{1-F\left(t_{i}\right)}\right)\right]=\beta \cdot \ln \left(t_{i}\right)-\beta \cdot \ln (\alpha)
$$

By introducing two auxiliary variables $x$ and $y$, whose expressions are defined in (4) and (5) respectively, (3) can be rewritten as in (6), which is the generic equation of a straight line featuring $\beta$ as slope and $\beta \cdot \ln (\alpha)$ as the intercept of the $y$-axis.

$$
\begin{gathered}
x=\ln \left(t_{i}\right) \\
y=\ln \left[\ln \left(\frac{1}{1-F\left(t_{i}\right)}\right)\right]
\end{gathered}
$$




$$
y=\beta \cdot x-\beta \cdot \ln (\alpha)
$$

Once the linearization process is completed, for every time-to-failure $t_{i}$, the Weibull CDF $F\left(t_{i}\right)$ needs to be estimated and the most widely used method consists in employing the median rank estimator, which relies on the Benard's approximation provided in (7) [22, 43].

$$
\widehat{F}\left(t_{i}\right)=\frac{i-0.3}{N+0.4}
$$

In (7), $i$ is the $i^{\text {th }}$ insulation breakdown considered and $N$ is the samples' population. Knowing both the time-to-failure $t_{i}$ (experimentally gathered) and the corresponding estimation of the Weibull $\operatorname{CDF} \hat{F}\left(t_{i}\right)$, these points are individuated on the probability plotting paper and the best possible straight line that fits the data set is found according to a linear regression (e.g. least squares method). Following this procedure, the Weibull probability plot is drawn and the parameters $\alpha$ (i.e. the time related to the $63.2 \%$ of the Weibull distribution function) and $\beta$ (i.e. the slope of the straight line) are obtained. Hence, the probability of failure at a generic time instant can be evaluated. For the aging temperatures 230,250 and $270{ }^{\circ} \mathrm{C}$, the Weibull probability plots with $95 \%$ confidence intervals are respectively reported in Figs. 7, 8 and 9, while the correspondent scale and shape parameters are listed in Table II.

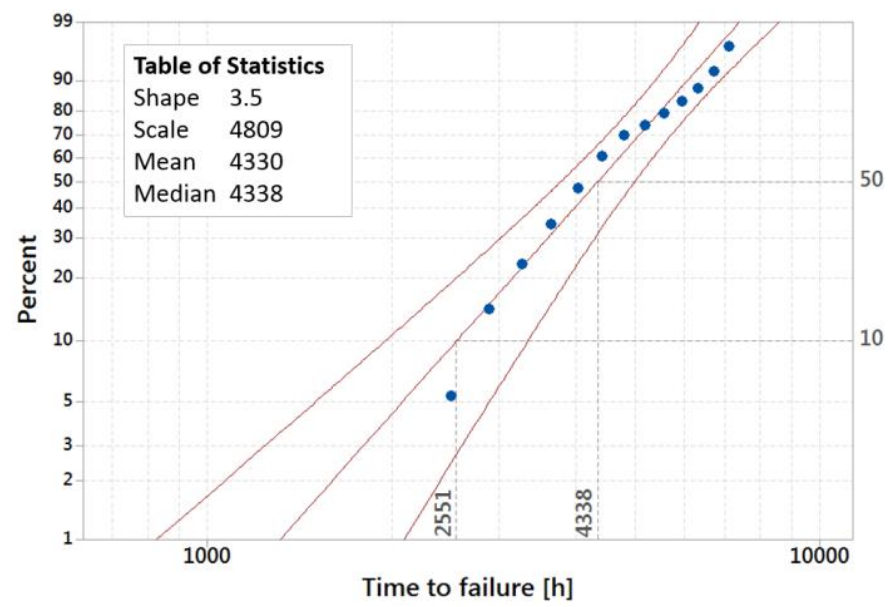

Fig. 7. Weibull probability plot for the time-to-failures at $230{ }^{\circ} \mathrm{C}$.

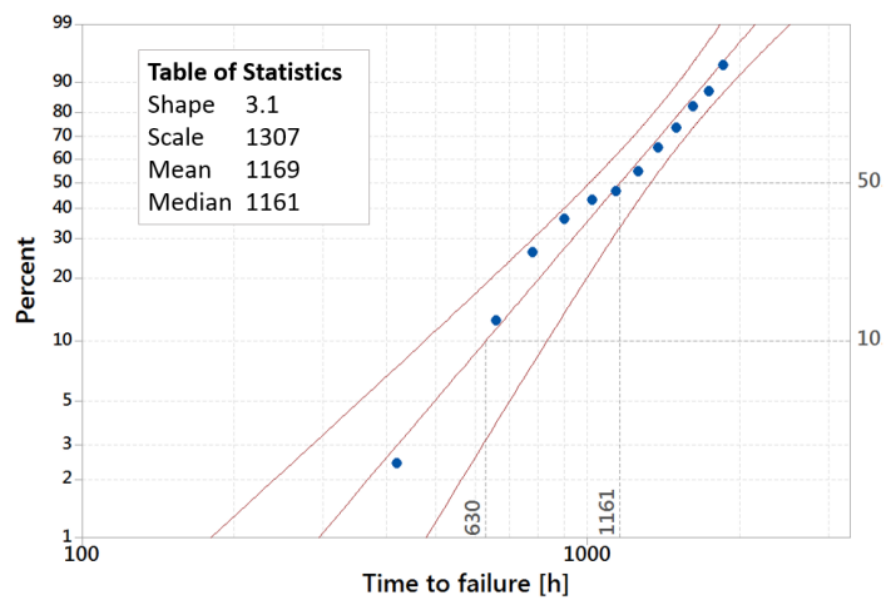

Fig. 8. Weibull probability plot for the time-to-failures at $250{ }^{\circ} \mathrm{C}$.

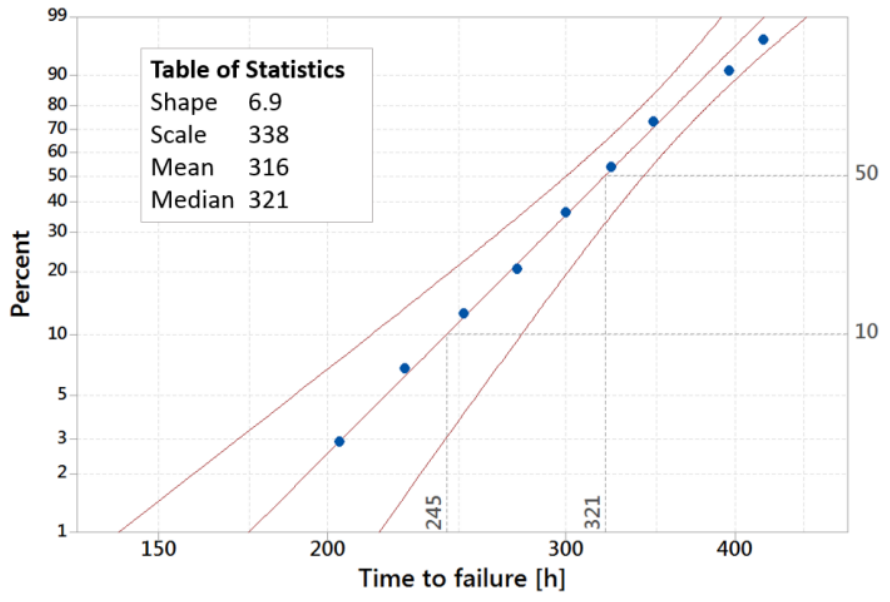

Fig. 9. Weibull probability plot for the time-to-failures at $270{ }^{\circ} \mathrm{C}$.

Considering the shape parameter values, the Weibull probability plot at $270{ }^{\circ} \mathrm{C}$ (i.e. Fig. 9) reveals an inflated shape parameter compared to those obtained at $230{ }^{\circ} \mathrm{C}$ and $250{ }^{\circ} \mathrm{C}$. Therefore, the time-to-failure at the highest aging temperature features a greater data variance due to both the glass-transition effect and the enamel detachment. The glass-transition effect is a secondary reaction triggered when the aging temperature is close to the polymer's glass-transition temperature. Hence, the polymer substrate changes from a rigid glassy material to a soft (but not melted) one, modifying its properties. In the specific case, the polyamide-imide is characterized by a glass-transition temperature of $275^{\circ} \mathrm{C}$ [48]. Additionally, the enamel insulation tends to become brittle with aging, thus the motorettes handling might be source of enamel detachment, which is more evident at $270{ }^{\circ} \mathrm{C}$, where the thermal aging impact is more significant. The Weibull probability plot also provides the lifetime percentiles $B \rho$, which indicate the time when a predetermined percentage of samples will 'die', e.g. B10 is the time associated at a $10 \%$ failure probability. For completeness, the time-to-failure related to $B 50$ (i.e. $50 \%$ percentile or median) and $B 10$ (i.e. $10 \%$ percentile) are included in Table II.

Table II Weibull parameters and failure time percentiles

\begin{tabular}{|c|c|c|c|c|}
\hline Temperature $\left[{ }^{\circ} \mathbf{C}\right]$ & $\boldsymbol{\alpha}[\mathbf{h}]$ & $\boldsymbol{\beta}[-]$ & $\boldsymbol{B 5 0}[\mathbf{h}]$ & $\boldsymbol{B 1 0}[\mathbf{h}]$ \\
\hline 230 & 4809 & 3.5 & 4337 & 2550 \\
\hline 250 & 1307 & 3.1 & 1160 & 629 \\
\hline 270 & 337 & 6.9 & 320 & 245 \\
\hline
\end{tabular}

In order to derive the lifetime in standard operating conditions, the Arrhenius plot (i.e. thermal endurance graph) of the tested specimens can be extrapolated, assuming that the Arrhenius model is valid for the three aging temperatures [43]. According to the reliability level required by the application at hand, different percentiles of the Weibull probability distribution can be adopted for determining the Arrhenius plot. For instance, the thermal endurance graph supplied by the magnet wire manufacturers is often referred to the 50\% percentile (i.e. $B 50$ ). However, choosing lower percentile values leads to more stringent reliability levels. For the three tested aging temperatures, the time-to-failures at various percentiles have been calculated and the resulting Weibull CDFs are shown in Fig. 10. With the purpose of establishing the Arrhenius plots 
at several percentiles, the Weibull CDFs are imported on the Arrhenius chart (i.e. log-log paper) and their location is identified consistently with the belonging temperature. Thus, a certain percentile is designated (e.g. 10\% percentile) and the associated thermal endurance curve is drawn by interpolating the three time-to-failures placed on the $\mathrm{CDFs}$ at the chosen percentile. An example of the ensuing Arrhenius curves is illustrated in Fig. 11, where the percentiles 10\% (i.e. B10) and $50 \%$ (i.e. $B 50$ ) are supposed.

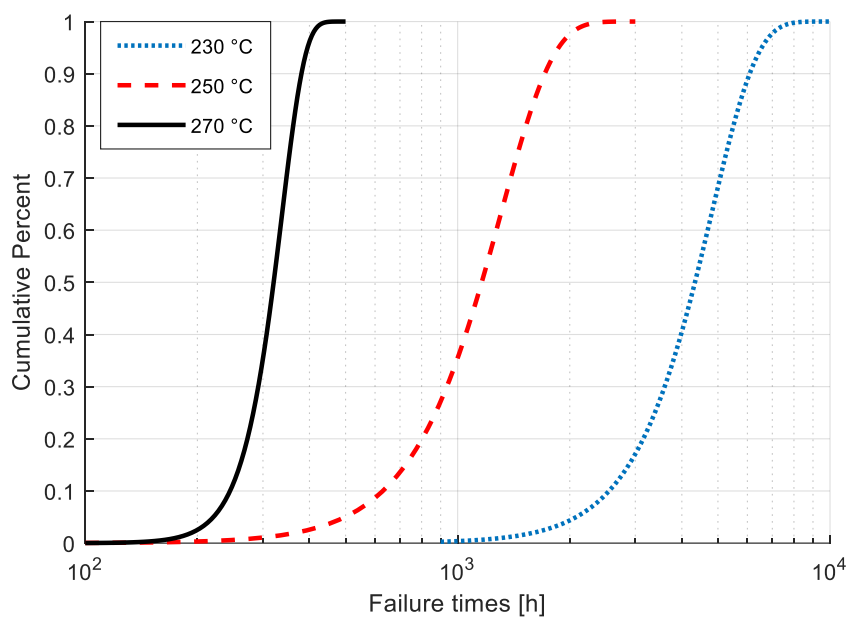

Fig. 10. Weibull CDFs for the three aging temperatures.

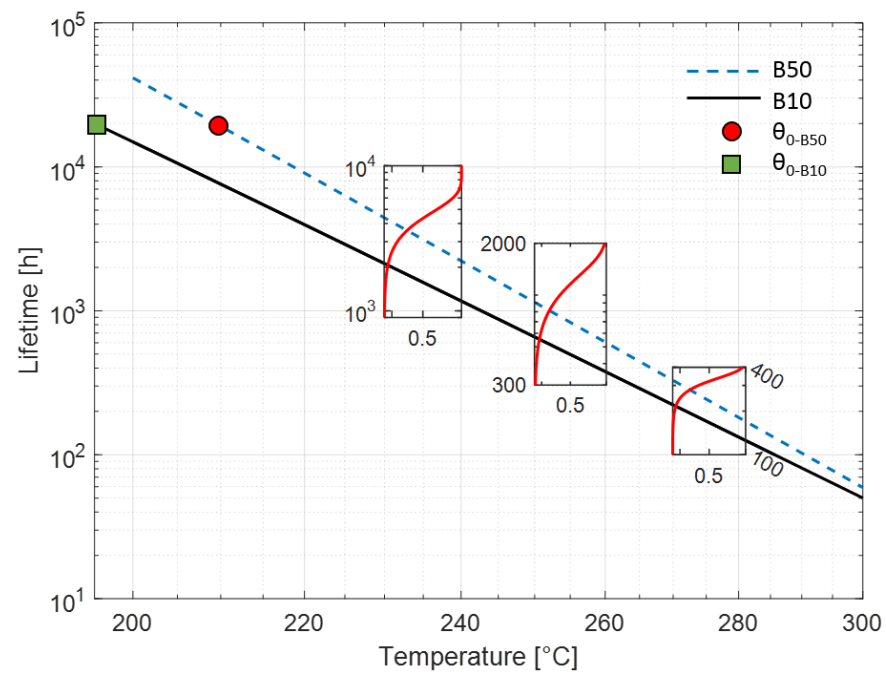

Fig. 11. Experimental Arrhenius curves at $B 10$ (black continuous line) and $B 50$ (blue dashed line) of the Weibull CDFs and thermal classes at $B 10$ (green square marker) and $B 50$ (red circle marker).

Despite the selected percentile in Fig. 11, it is worthy to underline that any other percentile could have been used, since its selection criterion depends on the demanded reliability level, as earlier mentioned. The Arrhenius curve is used to determine the thermal class, which is normally indicated as $\theta_{0}$. Since in the proposed approach several Arrhenius curves at different percentile can be drawn, the symbol $\theta_{0-B \rho}$ is employed to refer at the thermal class at a prescribed percentile $B \rho$.

\section{LIFETIME MODELLING AND STUDY-CASES}

Relying on the findings presented in the previous section, it is possible to build single-stress lifetime models able to predict the life of the turn-to-turn insulation, in case of PD-free low-voltage EMs (i.e. Type I insulation material), where the prevailing aging factor is the thermal stress. These life models are tailored / tuned on a specific percentile value (e.g. $50 \%, 10 \%$, etc.), which is contingent on the needed application's reliability figure. Consequently, they can be either used as analysis / validation tools for performing safety-checks on existing EMs or as reliability-oriented EM design tools to be integrated with 'standard' design models (i.e. thermal, electromagnetic, etc.). In the latter case, the EM duty cycle and the associated losses can be fed to the EM thermal model (e.g. lumped parameter thermal network) that will estimate the hot-spot winding temperature (hot-spot is preferred for a conservative forecast), which will then finally represent the input of the lifetime model. By comparing the obtained lifetime prediction (i.e. time-to-failure or cycles-to-failure) to the reliability specification demanded by the application (i.e. design constraint), it is checked whether the EM preliminary design fulfils the desired reliability level or not. In the affirmative case, the EM design can be finalized and the EM prototyped, on the contrary, the preliminary design should be revised and a new iteration is necessary, as depicted in the flowchart of Fig. 2. In the upcoming sub-sections, two single-stress lifetime models, for both continuous and variable duties, are discussed and some practical examples regarding their utilization are dispensed.

\section{A. Lifetime for continuous duty applications}

EMs working in continuous duty are characterized by a winding temperature that is almost constant throughout their whole operating period. Under this condition and assuming the thermal stress as the prevailing aging factor [27-29], a single-stress lifetime model based on Arrhenius-Dakin law is introduced for life prediction purposes [49]. In fact, the thermal endurance curves of Fig. 11 can be mathematically described by the Arrhenius-Dakin's equation (8), where $L_{B \rho}$ is the life at a given Weibull CDF percentile $B \rho, \theta$ is the generic absolute temperature expressed in Kelvin degrees, while $A_{B \rho}$ and $R_{B \rho}$ are characteristic parameters of the insulating material, which are functions of the reaction's activation energy.

$$
L_{B \rho}=A_{B \rho} \cdot \exp \left(R_{B \rho} / \theta\right)
$$

$A_{B \rho}$ and $R_{B \rho}$ have been graphically obtained from Fig. 11 and their values are listed in Table III for 10\% and 50\% percentiles.

Table III Parameters of the Arrhenius-Dakin equation

\begin{tabular}{|c|c|c|}
\hline Percentile & Parameters & Value \\
\hline \multirow{2}{*}{$10 \%$} & $A_{B 10}$ & $1.9 \cdot 10^{-12}[\mathrm{~h}]$ \\
\cline { 2 - 3 } & $R_{B 10}$ & $16028[\mathrm{~K}]$ \\
\hline \multirow{2}{*}{$50 \%$} & $A_{B 50}$ & $3.5 \cdot 10^{-11}[\mathrm{~h}]$ \\
\cline { 2 - 3 } & $R_{B 50}$ & $17793[\mathrm{~K}]$ \\
\hline
\end{tabular}

As previously stated, the Arrhenius curves in Fig. 11 allow also to extract the thermal class at a specific percentile of the time-to-failure (i.e. $\theta_{0-B \rho}$ ). This is defined as the temperature that guarantees at least 20,000 hours of continuous operation of the insulating material. Therefore, the resulting thermal class values corresponding to $10 \%$ (i.e. $\theta_{0-B 10}$ ) and $50 \%$ (i.e. $\theta_{0-B 50}$ ) percentiles are equal to $195.8^{\circ} \mathrm{C}$ and $209.3{ }^{\circ} \mathrm{C}$, respectively. Once the thermal class at a particular percentile (i.e. $\theta_{0-B \rho}$ ) is 
determined, the lifetime model for continuous duty EMs is developed by rearranging (8) as in (9) [27].

$$
L_{B \rho}=20,000 \cdot \exp \left[-R_{B \rho} \cdot\left(\frac{1}{\theta_{0-B \rho}}-\frac{1}{\theta}\right)\right]
$$

Supposing an EM working at continuous duty (i.e. constant temperature $\theta$ ), the life of its turn-to-turn insulation can be easily predicted for several failure probabilities (i.e. percentiles). This goal is achieved by replacing in (9) the hot-spot temperature $\theta$ coming from the EM thermal model and by choosing the desired Weibull CDF percentile, according to the reliability specification. For example, at a continuous temperature of $160{ }^{\circ} \mathrm{C}$, the expected $B 10$ lifetime is equal to $4.15 \cdot 105$ hours, whereas 1.34.106 hours is the life correspondent at $B 50$. For the sake of completeness, the outcomes in terms of lifetime are highlighted in Fig. 12, where the thermal endurance curves are reported on a more extensive temperature scale (i.e. $x$-axis scale) for both $B 10$ and $B 50$. Similarly, these results can be interpreted by stating that if $4.15 \cdot 105 \mathrm{EMs}$ are operated simultaneously for 1 hour at $160{ }^{\circ} \mathrm{C}$, then there is a $10 \%$ probability of facing a turn-to-turn insulation failure caused by thermal aging. Correspondingly, the 50\% probability of turn-to-turn breakdown will occur on a population of 1.34.106 EMs operating in the same conditions. Apart for the example provided, a different percentile can be employed and the EM's electromagnetic and thermal designs can be re-adapted with the aim of meeting the demanded reliability requirement.

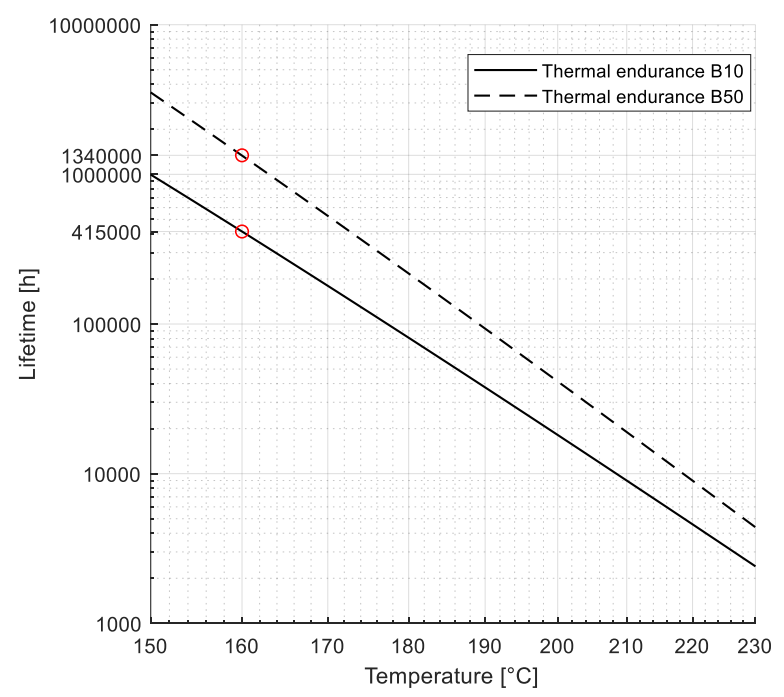

Fig. 12. Experimental thermal endurance curves at $B 10$ and $B 50$.

\section{B. Lifetime for variable duty applications}

Variable duty EMs are largely used in safety-critical systems, such as aerospace EMAs and automotive traction drives [17, 50]. Nonetheless, their insulation lifetime prediction is more complex than that for continuous duty EMs. Hence, an appropriate lifetime modelling approach can be reached by combining the Arrhenius' law with the cumulative damage law (i.e. Miner's law) [51]. Taking into account a generic time-variable temperature profile $\theta(t)$, whose time duration is indicated with $\Delta t_{\text {cycle }}$ (i.e. cycle's period), the insulation loss-of-life occurring during a single cycle (i.e. single temperature profile) at a specific Weibull CDF percentile is calculated as in (10).

$$
L F_{c y c l e-B \rho}=\int_{0}^{\Delta t_{c y c l e}} \frac{1}{L_{B \rho}\left[\theta_{i}(t)\right]} d t
$$

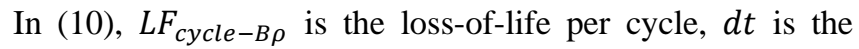
infinitesimal interval of the temperature profile during which the temperature is supposed to be constant, while $L_{B \rho}\left[\theta_{i}(t)\right]$ is the insulation life at the constant temperature $\theta_{i}(t)$ that is determined through (9) [52]. Relying on the cumulative damage law [51], the number of cycles-to-failure $K_{B \rho}$ relative to predetermined percentile can be computed using (11).

$$
K_{B \rho}=\frac{1}{L F_{\text {cycle }-B \rho}}
$$

Therefore, the turn-to-turn insulation will experience a breakdown when the cumulative loss-of-life reaches the unity value. Considering the insulation exposed to the thermal cycling, its total life $L_{t o t}$ can be expressed by (12).

$$
L_{\text {tot }}=K_{B \rho} \cdot \Delta t_{\text {cycle }}
$$

Having built the lifetime model for variable duty EMs, it can then be employed for predicting both the loss-of-life and the number of cycles-to-failure at different reliability levels (i.e. at several percentile). To prove the proposed methodology, two study-cases are examined, namely 1) an EM embedded in an EMA for aerospace application and 2) a traction EM installed on a fully-electric vehicle.

\section{B.1 Study-Case 1: EM for aerospace application}

In this study-case, an EMA intended for a helicopter nose landing gear retraction/extension mechanism is considered. The EMA is driven by a permanent magnet synchronous machine (PMSM) through a gearbox, whereas the PMSM is supplied by two-level power electronics converters based on conventional silicon IGBT (insulated gate bipolar transistor). From the preliminary design, a 12 slots / 10 poles combination is selected for the EM, featuring a surface-mount layout of PMs and a dual three-phase winding configuration [53], as illustrated in Fig. 13. The main parameters of the electric drive are summarized in Table IV. Analyzing the electric drive parameters, it is clear that the PD-free conditions mentioned in section II.B are satisfied.

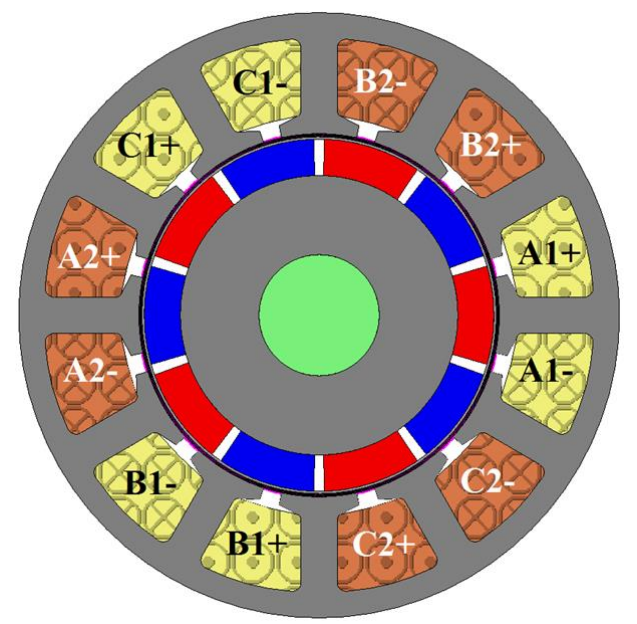

Fig. 13. Geometry and winding layout of the EM employed by the EMA. 
Table IV EMA's electric drive parameters

\begin{tabular}{|c|c|}
\hline Parameter & Data \\
\hline Slot number & 12 \\
\hline Pole number & 10 \\
\hline Rated Speed & $2500 \mathrm{rpm}$ \\
\hline Rated Torque & $1 \mathrm{Nm}$ \\
\hline Stack Length & $50 \mathrm{~mm}$ \\
\hline Stator Outer Diameter & $50 \mathrm{~mm}$ \\
\hline Copper fill factor & $\approx 0.5$ \\
\hline DC link voltage & $270 \mathrm{~V}$ \\
\hline Switching frequency & $10 \mathrm{kHz}$ \\
\hline Connection cable length & $2 \mathrm{~m}$ \\
\hline Cooling method & Naturally air cooled \\
\hline
\end{tabular}

When the EM preliminary design is completed (i.e. EM geometry and materials are known), the EM thermal model is built and used to predict the temperature distribution. In particular, the EM winding temperature trend ensuing from the fulfilment of an EMA mission profile is depicted in Fig. 14. The temperature profile (i.e. red line in Fig. 14) starts from $70{ }^{\circ} \mathrm{C}$ (i.e. ambient temperature), because a worst-case scenario is purposely evaluated. Under the assumption of thermal stress as prevailing aging factor, such a temperature profile (i.e. temperature vs. time) is fed as input to (10), whose integral is numerically solved via a Matlab® script, in order to predict the loss-of-life associated to a single EMA mission profile (i.e. single thermal cycle). Since the lifetime model $L_{B \rho}\left[\theta_{i}(t)\right]$ applied within the infinitesimal time interval can be tuned at specific percentile (see section V.A), the resulting loss-of-life would account for the chosen reliability figure. For instance, selecting the Weibull CDF $10 \%$ and $50 \%$ percentiles, the relative instantaneous loss-of-life functions are plotted in Fig. 14, i.e. dashed and continuous black lines respectively. These findings are summarized in Table $\mathrm{V}$, where the predicted cycles-to-failure (i.e. $K_{B \rho}$ ) are provided along with the loss-of-life per cycle (i.e. $L F_{c y c l e-B \rho}$ ), for both $10 \%$ and $50 \%$ percentiles.

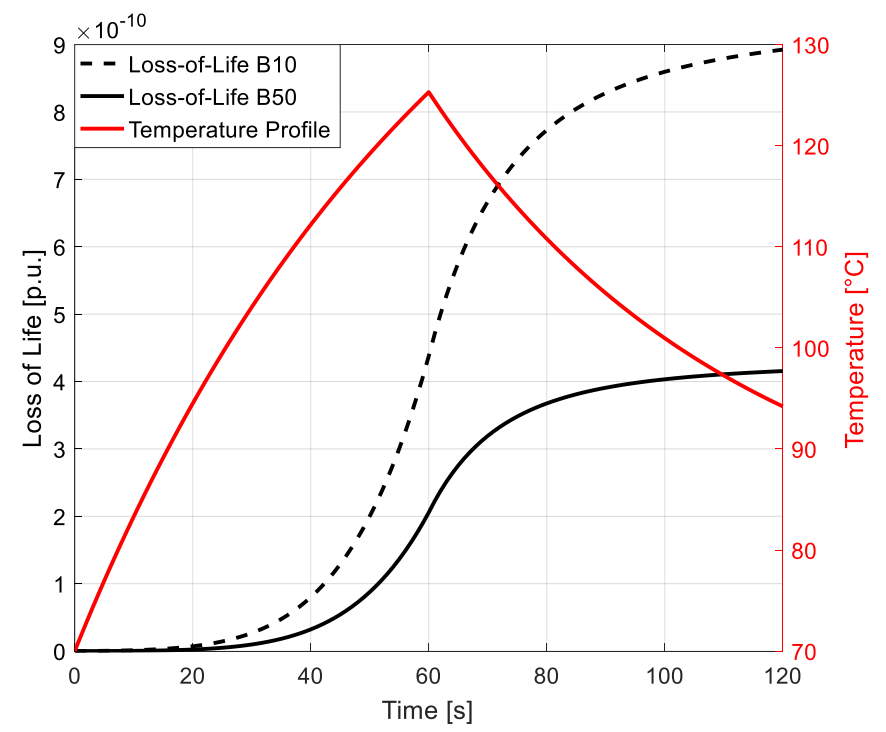

Fig. 14. EM's hot-spot winding temperature trend (red line) over a single EMA mission profile and corresponding loss-of-life for both $10 \%$ (black dashed line) and 50\% (black continuous line) percentiles.
Focusing on the $K_{E M A-B 10}$ value, it is possible to assert that the turn-to-turn insulation would feature a $10 \%$ breakdown probability after 1.1.109 EMA activations (i.e. EMA mission profiles) and this failure probability is only to be ascribed to the thermal stress. Although the number of activations might seem extremely high, it is important to underline that aerospace EMAs are required to operate with extremely low failure probability, due to the application's safety-critical nature. Hence, a percentile lower than $10 \%$ (e.g. $1 \%$ percentile) might be considered for EMs employed in aerospace applications. Referring to the flowchart in Fig. 2, if the predicted cycles-to-failure comply with the EMA reliability requirement, the EM can then be prototyped, otherwise changes at EM preliminary design need to be implemented.

Table IV Aerospace EMA study-case: loss-of-life and cycles-to-failure at $10 \%$ and $50 \%$ percentiles

\begin{tabular}{|c|c|c|}
\hline Percentile & Parameter & Value \\
\hline \multirow{2}{*}{$10 \%$} & $L F_{E M A-B 10}$ & $8.93 \cdot 10^{-10}$ [p.u.] \\
\cline { 2 - 3 } & $K_{E M A-B 10}$ & $1.1 \cdot 10^{9}[\mathrm{cycles}]$ \\
\hline \multirow{2}{*}{$50 \%$} & $L F_{E M A-B S 0}$ & $4.16 \cdot 10^{-10}$ [p.u.] \\
\cline { 2 - 3 } & $K_{E M A-B 50}$ & $2.4 \cdot 10^{9}[$ cycles] \\
\hline
\end{tabular}

\section{B.2 Study-Case 2: EM for traction application}

The second study-case analyses a fully-electric minivan, where the mechanical power required at its wheels is provided by two identical EMs and a stepdown gearbox is placed between every EM and the wheelbase (i.e. one EM per vehicle axle). This architecture ensures an appropriate level of redundancy and availability of the entire system. The EM is a 24 slots / 20 poles, interior PMSM and its geometry, resulting from the preliminary design, is depicted in Fig. 15. The PMSM is directly connected to the power electronics converter (i.e. integrated drive) and the electric drive parameters are detailed in Table VI. As per the first study-case analysed, also for this application the PD-free requirements are met. Hence, under the assumption of thermal predominant aging stress, the lifetime model developed for variable duty service is here used to estimate both the loss-of-life and the cycles-to-failure of the traction EM's turn-to-turn insulation.

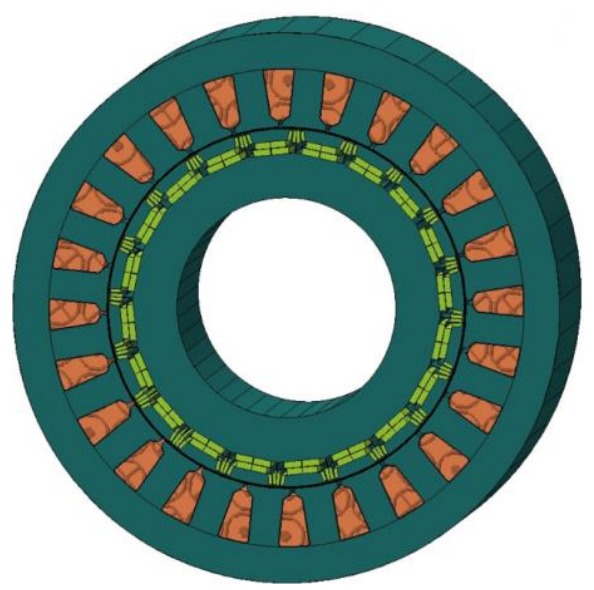

Fig. 15. Geometry of the EM used for the automotive study-case.

As for most automotive applications, the EM's temperature profile depends on the vehicle drive cycle, as well as, the EM's 
characteristics, such as thermal loading and cooling method. A standard extra urban driving cycle (EUDC) is picked because of its demanding driving speed and this is periodically performed over one hour time window. Similarly to the previous study-case, the EM's hot-spot winding temperature is obtained through the EM thermal model, as shown in Fig. 16 (red continuous line). This temperature profile refers to an ambient temperature of $25{ }^{\circ} \mathrm{C}$ and an inlet temperature of $40{ }^{\circ} \mathrm{C}$ for the cooling liquid. In this example, the temperature exceeds the insulation thermal class (i.e. $200{ }^{\circ} \mathrm{C}$ ) for short time periods, leading to a considerable loss-of-life. Equation (10), describing the Arrhenius-Miner lifetime model, is adopted to predict the loss-of-life per hour and the corresponding loss-of-life functions are reported in Fig. 16, for both 10\% (black dashed line) and $50 \%$ (black continuous line) percentiles. For the sake of completeness, the hourly loss-of-life values are listed in Table VII, besides the predicted number of cycles-to-failure. The latter is calculated as given in (11), where $\Delta t_{\text {cycle }}$ is set equal to 1 hour in the present study-case.

Table VI Electric drive parameters of the automotive study-case

\begin{tabular}{|c|c|}
\hline Parameter & Data \\
\hline Slot number & 24 \\
\hline Pole number & 20 \\
\hline Rated Speed & $4500 \mathrm{rpm}$ \\
\hline Rated Torque & $150 \mathrm{Nm}$ \\
\hline Stack Length & $130 \mathrm{~mm}$ \\
\hline Stator Outer Diameter & $250 \mathrm{~mm}$ \\
\hline Copper fill factor & $\approx 0.5$ \\
\hline DC link voltage & $270 \mathrm{~V}$ \\
\hline Switching frequency & $10 \mathrm{kHz}$ \\
\hline Connection cable length & $<0.5 \mathrm{~m}$ \\
\hline Cooling method & Forced liquid cooled \\
\hline
\end{tabular}

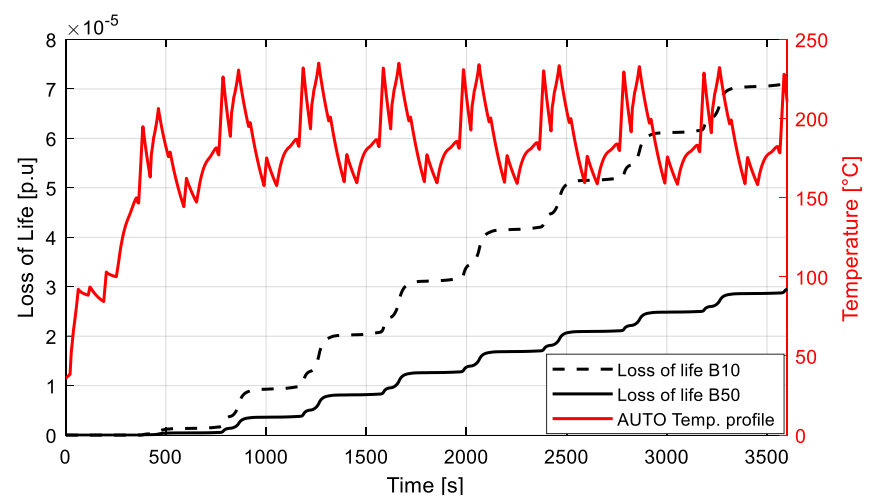

Fig. 16. EM's hot-spot winding temperature profile (red line) over one hour EUDC and hourly loss-of-life for both 10\% (black dashed line) and 50\% (black continuous line) percentiles.

As an outcome of the lifetime assessment, it is possible to claim that if 13,700 EMs are operated with the EUDC during 1 hour, then $10 \%$ of them would fail because of a turn-to-turn insulation breakdown caused by thermal aging. Despite the fact of accounting for just the thermal aging factor, the simulated EUDC is highly conservative from the lifetime consumption point of view. Indeed, the study is carried out under the assumption that throughout its whole lifetime, the electric vehicle is driven on extra urban roads only and frequent thermal overloads occur, as highlighted by the temperature profile of Fig. 16 (i.e. red continuous line). Nevertheless, it is worthy to emphasize that the gathered results are in line with the lifetime expectancy of a traction EM for automotive, which is generally set to 10,000 hours or $300,000 \mathrm{~km}$.

Table VII Automotive study-case: loss-of-life and cycles-to-failure at $10 \%$ and $50 \%$ percentiles

\begin{tabular}{|c|c|c|}
\hline Percentile & Parameter & Value \\
\hline \multirow{2}{*}{$10 \%$} & $L F_{\text {AUTO-BIO }}$ & $7.28 \cdot 10^{-5}$ [p.u.] \\
\cline { 2 - 3 } & $K_{\text {AUTO-BIO }}$ & $1.37 \cdot 10^{4}$ [cycles] \\
\hline \multirow{2}{*}{$50 \%$} & $L F_{\text {AUTO-B50 }}$ & $1.92 \cdot 10^{-12}$ [p.u.] \\
\cline { 2 - 3 } & $K_{\text {AUTO-B50 }}$ & $3.39 \cdot 10^{4}$ [cycles] \\
\hline
\end{tabular}

\section{CONCLUSIONS}

Within the EM and drives community, the reliability of components is drawing an ever-increasing attention and this is currently matter of intense research activity. Therefore, the present paper proposed a reliability-oriented EM design approach aiming at overcoming the adoption of over-engineering measures to achieve the required reliability figures. Such a paradigm shift addresses the necessity of complying with the stringent power density and reliability constraints demanded by the modern EMs for transportation applications. In this work, the suggested approach deals with the turn-to-turn insulation sub-system (i.e. weakest insulation point) of low-voltage random-wound EMs and specifically targets the aging ensuing from the thermal stress. Accelerated thermal aging tests are carried out for building single-stress lifetime models for both continuous and variable duty EM services, which offer the possibility of being tuned according to the reliability level (i.e. percentiles) of the application at hand. The applicability of the described methodology, which enables the reliability-oriented EM design, was proven by addressing several example of implementation related to realistic applications counting continuous and variable duty services.

Although the experimental tests are performed on a particular enamelled magnet wire and the findings can be directly used in the design of EMs employing the same insulation, a general procedure is outlined for determining the suitable lifetime model's parameters corresponding to a different magnet wire topology. The introduced single-stress lifetime models deliver an accurate prediction only when the thermal stress is the prevailing aging factor. For this reason, the research end-game consists in developing multi-stress lifetime models for a more advanced and comprehensive lifetime forecast. Nonetheless, this goal can only be reached by first developing and then migrating / extending the single-stress lifetime models here discussed, in order to include other aging factors, such as electrical, mechanical and environmental.

\section{REFERENCES}

[1] M. Rosu, P. Zhou, D. Lin, et al "Multiphysics Simulation by Design for Electrical Machines, Power Electronics and Drives", Wiley-IEEE Press.

[2] A. Al-Timimy, et al., "Design and losses analysis of a high power density machine for flooded pump applications," IEEE Transactions on Industry Applications, vol. 54, no. 4, pp. 3260-3270, July 2018.

[3] M. Van der Geest, et al., "Power Density Limits and Design Trends of High-Speed Permanent Magnet Synchronous Machines", in IEEE Trans. on Transportation Electrification, vol. 1, no. 3, 2015. 
[4] V. Madonna, et al., "Improved Thermal Management and Analysis for Stator End-Windings of Electrical Machines," IEEE Transactions on Industrial Electronics, vol. 66, pp. 5057-5069, 2019.

[5] "Transport Roadmaps - A guide to low carbon vehicle, energy and infrastructure roadmaps" UK Deparment for Transport; Sep. 2015.

[6] Lukic, M., et al., "State of the art of electric taxiing systems" 2018 IEEE Electrical Systems for Aircraft, Railway, Ship Propulsion and Road Vehicles-Int. Transportation Electrification Conf. (ESARS-ITEC), Nottingham, UK, 2018, pp. 1-6.

[7] "Flightpath 2050 - Europe's Vision for Aviation, Report of the High Level Group on Aviation Research, EU Commission," Directorate-General for Mobility and Transport; 2011.

[8] P. Giangrande, et al., "Considerations on the development of an electric drive for a secondary flight control electromechanical actuator", IEEE Trans. on Industry Applications, vol. 55, no. 4, pp. 3544-3554, 2019.

[9] A. Al-Timimy, et al., "Comparative study of permanent magnetsynchronous and permanent magnet-flux switching machines for high torque to inertia applications," in 2017 IEEE Workshop on Electrical Machines Design Control and Diagnosis, pp 45-51, Nottingham, UK, April 2017.

[10]M. Popescu, et al., "Modern Heat Extraction Systems for Power Traction Machines - A Review," IEEE Transactions on Industry Applications, vol. 52, pp. 2167-2175, 2016.

[11]Z. Xu, et al., "Thermal management of a permanent magnet motor for a directly coupled pump," in International Conference on Electrical Machines (ICEM), 2016.

[12] G. C. Stone, et al. "Electrical Insulation for Rotating Machines: Design, Evaluation, Aging, Testing, and Repair", Wiley, 2014.

[13] V. Madonna, P. Giangrande, L. Lusuardi, A. Cavallini, C. Gerada, and M. Galea, "Thermal overload and insulation aging of short duty cycle, aerospace motors, " in press on IEEE transactions on Industrial Electronics, 2019.

[14] Y. Merizalde, L. Hernández-Callejo, and O. Duque-Perez, "State of the Art and Trends in the Monitoring, Detection and Diagnosis of Failures in Electric Induction Motors," Energies, vol. 10, p. 1056, 2017.

[15] Madonna, V., Giangrande, P., Gerada, C., et al., "Thermal analysis of faulttolerant electrical machines for aerospace actuators," IET Electric Power Applications, vol. 13, no. 7, pp. 843-852, 2018.

[16]B. J. Moore, R. H. Rehder, and R. E. Draper, "Utilizing reduced build concepts in the development of insulation systems for large motors," in Proceedings: Electrical Insulation Conference and Electrical Manufacturing and Coil Winding Conference, 1999, pp. 347-352.

[17] V. Madonna, P. Giangrande, and M. Galea, "Evaluation of strand-to-strand capacitance and dissipation factor in thermally aged enamelled coils for low-voltage electrical machines," IET Science, Measurement \& Technology, vol. 13, no. 8, pp. 1170-1177, 2019.

[18] K. C. Kapur and M. Pecht, Reliability Engineering. Hoboken, New Jersey: John Wiley \& Sons, 2014.

[19]M. Galea, P. Giangrande, V. Madonna, and G. Buticchi, "Insulation systems for electrical machines: Reliability MUST become a main design objective," IEEE Industrial Electronics Magazine, vol. 14, no. 1, 2020.

[20]N. Lahoud, et al., "Electrical Aging of the Insulation of Low-Voltage Machines: Model Definition and Test With the Design of Experiments" IEEE Trans. on Ind. Electronics, vol. 60, no. 9, pp. 4147-4145, 2013.

[21] V. Madonna, P. Giangrande and M. Galea, "Introducing Physics of Failure Considerations in the Electrical Machines Design," in IEEE IEMDC, San Diego, USA, 2019.

[22]Eyad A. Feilat, "Lifetime Assessment of Electrical Insulation, Electric Field”, IntechOpen, Sheikholeslami Kandelousi, May 2018, Available https://www.intechopen.com/books/electric-field/lifetime-assessment-ofelectrical-insulation.

[23]A.C. Gjerde, "Multifactor ageing models - origin and similarities," IEEE Electrical Insulation Magazine, vol. 13, pp. 6-13, 1997.

[24] G.M. Montanari, G. Mazzanti and L. Simoni "Progress in Electrothermal Life Modeling of Eleckical Insulation during the Last Decades," IEEE Transactions on Dielectrics and Electrical Insulation, vol. 9, no. 5, pp. 730745, October 2002.

[25]G. Mazzanti, G.C. Montanari, L. Simoni, and M.B. Srinivas, "Combined electro-thermo-mechanical model for life prediction of electrical insulating materials," Conference on Electrical Insulation and Dielectric Phenomena, Virginia Beach, VA, USA, 1995.

[26]P. Cygan and J. R. Laghari, "Models for insulation aging under electrical and thermal multistress," IEEE Transactions on Electrical Insulation, vol. 25, pp. 923-934, 1990.

[27] G. C. Montanari and L. Simoni, "Aging phenomenology and modeling,"
IEEE Transactions on Electrical Insulation, vol. 28, pp. 755-776, 1993.

[28]I.J. Voitto, "Electrical Ageing in Lifetime Estimation of Hydroelectric Generator Stator Windings," XIX International Conference on Electrical Machines (ICEM), Rome, 2010.

[29]"IEC 60505:2011 Evaluation and qualification of electrical insulation systems," ed: IEC, 2011.

[30]M. Fernando, et al., "Condition Assessment of Stator Insulation during Drying, Wetting and Electrical Ageing," IEEE Transactions on Dielectrics and Electrical Insulation, vol. 20, no. 6, pp. 2081-2090, 2013.

[31]P. Giangrande, S. V. Bozhko, C. I. Hill and C. Gerada, "A Novel MultiLevel Electro-Mechanical Actuator Virtual Testing and Analysis Tool," in 7th IET International Conference on Power Electronics, Machines and Drives (PEMD 2014), 2014.

[32] A. Cavallini, D. Fabiani, and G. C. Montanari, "Power electronics and electrical insulation systems - Part 1: Phenomenology overview," IEEE Electrical Insulation Magazine, vol. 26, no. 3, pp. 7-15, 2010.

[33]Z. Huang, T. Yang, P. Giangrande, S. Chowdhury, M. Galea, and P. Wheeler, "An active modulation scheme to boost voltage utilization of the dual converter with a floating bridge," IEEE Transactions on Industrial Electronics, vol. 66, no. 7, pp. 5623-5633, 2019.

[34] V. Madonna, P. Giangrande, W. Zhao, G. Buticchi, H. Zhang, C. Gerada, et al., "Reliability vs. Performances of Electrical Machines: Partial Discharges Issue", in IEEE WEMDCD, 2019.

[35] V. Madonna, P. Giangrande, W. Zhao, H. Zhang, C. Gerada, and M. Galea, "On the Design of Partial Discharge-Free Low Voltage Electrical Machines," in IEEE IEMDC, San Diego, USA, 2019.

[36]"IEC 60034-18-41:2014 Rotating electrical machines - Part 18-41: Partial discharge free electrical insulation systems (Type I) used in rotating electrical machines fed from voltage converters - Qualification and quality control tests ", ed: IEC, 2014.

[37]D. Fabiani "Accelerated degradation of AC-motor winding insulation due to voltage waveform generated by adjustable speed drivers", Ph.D. dissertation, University of Bologna, Italy 2002.

[38] "IEEE Standard Test Procedure for Thermal Evaluation of Systems of Insulating Materials for Random-Wound AC Electric Machinery," IEEE Std 117-2015 (Revision of IEEE Std 117-1974), pp. 1-34, 2016.

[39]"IEC 60034 18-21: Functional evaluation of insulation systems - Test procedures for wire-wound windings - Thermal Evaluation and classification," ed, 2012.

[40]T.J. Murray, "Poly(amide-imides): Wire Enamels with Excellent Thermal and Chemical Properties", in Macromolecular Materials and Engineering, vol. 293, no. 5, pp. 350 - 360, May 2008.

[41]S.A. Odhano, P. Giangrande, R. Bojoi, and C. Gerada, "Selfcommissioning of interior permanent magnet synchronous motor drives with high-frequency current injection," in 2013 Energy Conversion Congress and Exposition (ECCE), pp. 3852-3859, 2013.

[42] "IEC 60317-0-1:2013 Specifications for particular types of winding wires - Part 0-1: General requirements - Enamelled round copper wire," ed: IEC, 2013.

[43]P. Mancinelli, S. Stagnitta, and A. Cavallini, "Qualification of Hairpin Motors Insulation for Automotive Applications," IEEE Transactions on Industry Applications, vol. 53, pp. 3110-3118, 2017.

[44] C. Zoeller, et al., "Evaluation and Current-Response-Based Identification of Insulation Degradation for High Utilized Electrical Machines in Railway Application," IEEE Trans. on Industry Applications, vol. 53, no. 3, 2017.

[45] M. Farahani, et al., "Behaviour of Machine Insulation Systems Subjected to Accelerated Thermal Aging Test," IEEE Trans. on Dielectrics and Electrical Insulation, vol. 17, no. 5, 2010.

[46] "ASTM D2307-07a(2013): Standard Test Method for Thermal Endurance of Film-Insulated Round Magnet Wire," ed. ASTM International, West Conshohocken, PA, 2013.

[47]L.A. Escobar and W.Q. Meeker, "A Review of Accelerated Test Models" on Statistical Science, Vol. 21, No. 4, pp 552-577, 2006.

[48]D.J. Liaw and W.H. Chen, "High glass transitions of novel organo-soluble polyamide-imides based on noncoplanar and rigid diimide-icarboxylic acid," Polymer Degradation and Stability, vol. 91, no. 8, pp. 1731-1739, 2006.

[49]T. W. Dakin, "Electrical Insulation Deterioration Treated as a Chemical Rate Phenomenon," Transactions of the American Institute of Electrical Engineers, vol. 67, pp. 113-122, 1948.

[50]C. Sciascera, et al., "Optimal design of an electro-mechanical actuator for aerospace application," in IECON 2015 - 41st Annual Conference of the IEEE Industrial Electronics Society, 2015, pp. 1903-1908.

[51]E. Wilkins, "Cumulative damage in fatigue," in Colloquium on Fatigue/Colloque de Fatigue/Kolloquium über Ermüdungsfestigkeit, 1956, 
pp. 321-332

[52]G. Mazzanti, "Analysis of the Combined Effects of Load Cycling, Thermal Transients, and Electrothermal Stress on Life Expectancy of High-Voltage AC Cables," IEEE Transactions on Power Delivery, vol. 22, no. 4, pp. 2000-2009, 2007.

[53]P. Giangrande, V. Madonna, S. Nuzzo, C. Spagnolo, C. Gerada, and M. Galea, "Reduced Order Lumped Parameter Thermal Network for Dual Three-Phase Permanent Magnet Machines," in IEEE WEMDCD, 2019.

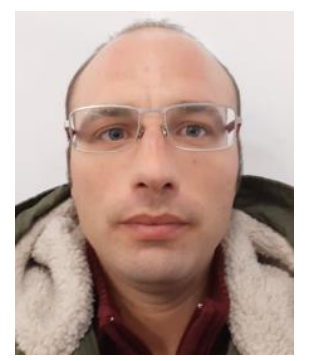

Paolo Giangrande (M'12-SM'19) received the Bachelor's (Hons.) and Master's (Hons.) degrees in electrical engineering at the Politecnico of Bari in 2005 and 2008, respectively. He received his $\mathrm{PhD}$ in electrical engineering at the Politecnico of Bari in 2011. Since 2012, he was Research Fellow at the University of Nottingham (UK), within the Power Electronics, Machines and Control Group. In 2018, he was appointed Senior Research Fellow and he is currently head of the Accelerated Lifetime Testing Laboratory at the Institute of Aerospace Technology, Nottingham. His main research interests include sensorless control of AC electric drives, design and testing of electromechanical actuators for aerospace, thermal management of high-performance electric drives and lifetime modelling of electrical machines.

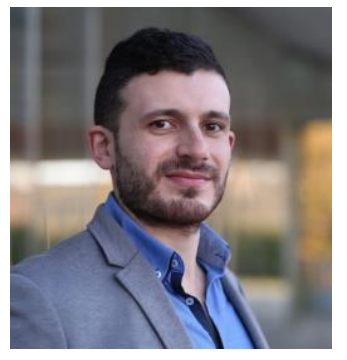

Vincenzo Madonna (S'17) received the $\mathrm{BSc}$ degree in Electronic Engineering from the University of Calabria, Italy, in 2012, and the MSc degree in Electrical Engineering from the University of Bologna, Italy, in 2016. In the same year he was awarded the prestigious Marie Sklodowska-Curie Fellowship and he joined the Institute for Aerospace Technology at the University of Nottingham, UK as a Doctoral Fellow in reliability-oriented design of electrical machines for transportation. Vincenzo is currently a Research Fellow with the Propulsion Futures Beacon of Excellence at the University of Nottingham. During his $\mathrm{PhD}$ studies he has authored more than 20 scientific papers. His research interests include design, thermal management and lifetime prediction modelling of electrical machines.

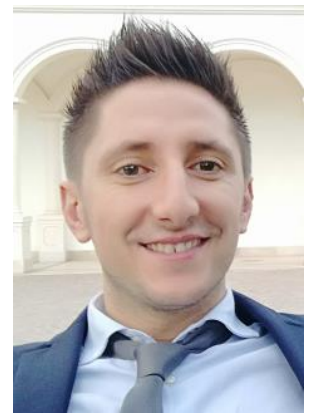

Stefano Nuzzo (M'18) received the B.Sc. and M.Sc. degrees in electrical engineering from the University of Pisa, Pisa, Italy, in 2011 and 2014, respectively, and the Ph.D. degree in electrical engineering from the University of Nottingham, Nottingham, U.K., in 2018. He is currently a Research Fellow with the Power Electronics, Machines and Control Group, University of Nottingham. He has also been a Research Fellow with the Department of Engineering Enzo Ferrari, University of Modena and Reggio Emilia, Modena, Italy, since 2019. His research interests are the analysis, modeling, and optimizations of electrical machines, with a focus on salient-pole synchronous generators and brushless excitation systems for industrial power generation applications. He is also involved in a number of diverse projects related to the more electric aircraft initiative and associated fields. Dr. Nuzzo is a member of the IEEE Industrial Electronics Society and the IEEE Industry Applications Society. He constantly serves the scientific community as a reviewer for several journals and conferences.

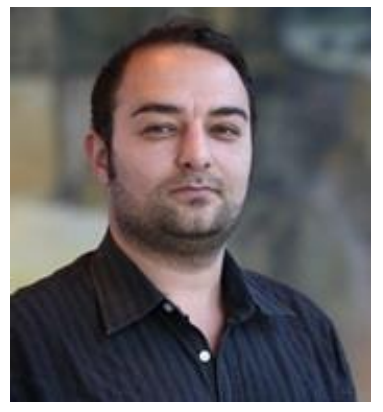

Michael Galea (M'13-SM'18, FRAeS) received the Ph.D. degree in electrical machines design in 2013 from the University of Nottingham, Nottingham, U.K. He was appointed as Lecturer in 2014, as Associate Professor in 2018 and as Professor in Electrical Machines and Drives in 2019, all with the University of Nottingham. $\mathrm{He}$ currently lectures in Electrical Machines and Drives and in Aerospace Systems Integration and manages a number of diverse projects and programmes related to the more/all electric aircraft, electrified propulsion, and associated fields. His main research interests include design and development of electrical machines and drives (classical and unconventional), reliability and lifetime degradation of electrical machines and the more electric aircraft. Michael is a Fellow of the Royal Aeronautical Society and a Senior Member of the IEEE. Michael also serves an Associate Editor for the IEEE Transactions on Industrial Electronics and for the IET Electrical Systems in Transportation. 